\title{
HYPERICUM SP. EXTRACTS IMPROVE ANXIETY-LIKE BEHAVIOUR AND INFLUENCE CEREBRAL HMOX1 EXPRESSION IN A RAT MODEL OF FG-7142 - INDUCED ANXIETY
}

\author{
ALEXANDRA C. SEVASTRE-BERGHIAN ${ }^{1 \#}$, VLAD A. TOMA ${ }^{2}$, BOGDAN SEVASTRE $^{3}$, \\ DANIELA BENEDEC ${ }^{4}$, ILIOARA ONIGA ${ }^{4}$, LORENA FILIP $^{4 \#}$, IOANA BÂLDEA ${ }^{1}$, ŞOIMIŢA \\ SUCIU ${ }^{1}$, CRISTIAN PAUL POPOVICI $^{3}$, ROXANA LIANA LUCACIU ${ }^{4}$, NICOLETA DECEA ${ }^{1}$, \\ SIMONA V. CLICHICI ${ }^{1}$, IRINA IELCIU ${ }^{4}$, GABRIELA A. FILIP ${ }^{1 *}$, DANIELA HANGANU ${ }^{4}$

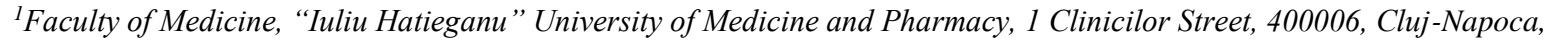 \\ Romania \\ ${ }^{2}$ NIRD for Isotopic and Molecular Technologies, Department of Molecular and Biomolecular Physics, 101 Donat Street, \\ Cluj-Napoca, Romania \\ ${ }^{3}$ Faculty of Veterinary Medicine, University of Agricultural Science and Veterinary Medicine, 3-5 Mănăştur Street, 400372 , \\ Cluj-Napoca, Romania \\ ${ }^{4}$ Faculty of Pharmacy, "Iuliu Hatieganu” University of Medicine and Pharmacy, 8 Victor Babeș Street, 400012, Cluj- \\ Napoca, Romania
}

*corresponding author: adrianafilip33@yahoo.com

${ }^{\#}$ Authors with equal contribution.

Manuscript received: April 2021

\begin{abstract}
The aim of this study was to evaluate the effects of Hypericum maculatum (HM) and Hypericum perforatum (HP) dry extracts compared to quercetin (Q), on ambulatory activity and GABA levels on FG-7142 (FG) induced anxiety model in Wistar rats. Histopathological changes in hippocampus and frontal lobe and heme oxygenase 1 (HMOX1) immunoreactivity in frontal cortex were also investigated. Q (30 mg/kg bw) increased gamma-aminobutyric acid (GABA) levels in the frontal lobe, enhanced general locomotion and central exploration behaviour in the open field test (OFT) and elevated plus maze (EPM). Both Hypericum sp. extracts (HpE) administered in doses of $350 \mathrm{mg} / \mathrm{kg}$ bw improved central locomotion in OFT. Quercetin administration increased HMOX1 expression whereas both extracts decreased HMOX1 immunoreactivity in frontal cortex neurons. To conclude, HpE may improve anxiety-like behaviour and modulate HMOX1 immunoreactivity in frontal cortex neurons.

\section{Rezumat}

Scopul acestui studiu a fost de a evalua efectele extractelor uscate de Hypericum maculatum (HM) și Hypericum perforatum (HP) comparativ cu quercitina (Q), asupra activității fizice și nivelului GABA, pe model de anxietate indusă de FG-7142 (FG), la șobolani Wistar. Au fost, de asemenea, investigate modificările histopatologice de la nivelul hipocampului și ale lobului frontal și imunoreactivitatea hemoxigenazei în cortexul frontal. Q (30 mg $/ \mathrm{kg}$ corp) a crescut nivelul acidului gama-aminobutiric (GABA) în lobul frontal, a îmbunătățit locomoția generală și comportamentul de explorare în zona centrală în cadrul testelor open field (OFT) și elevated plus maze (EPM). Ambele extracte de Hypericum sp. (HpE), administrate în doză de $350 \mathrm{mg} / \mathrm{kg}$ corp, au îmbunătătit locomoția centrală în OFT. Administrarea de quercetină a crescut expresia HMOX1, în timp ce ambele extracte testate au redus imunoreactivitatea HMOX1 în neuronii cortexului frontal. În concluzie, extractele de Hypericum sp. pot îmbunătăți comportamentul de tip anxios și pot modula imunoreactivitatea HMOX1 în neuronii cortexului frontal.
\end{abstract}

Keywords: Hypericum maculatum, Hypericum perforatum, GABA, HMOX1, anxiety

\section{Introduction}

Anxiety is a negative emotional response to a threat or potential threat, characterized by apprehension, feelings of worry and specific behavioural patterns. When this emotion is inappropriate, highly intense and persistent, it interferes with the ability to cope successfully with life challenges and it can be considered pathological [18, 22, 31]. According to the World Health Organization (WHO), in 2019, a total of 275 million people were estimated to suffer from anxiety disorders, namely $4 \%$ of the global adult population, thus being reported as the most common mental disorder worldwide [14]. Anxiety is a complex multifactorial disease in which inflammation, oxidative stress, alterations of iron homeostasis, immune and endocrine pathways are involved [15, 21]. Redox imbalance due to excessive free radical production or alteration of antioxidant enzymes activity including glutathione peroxidase (GPx)-1, glutathione reductase (GR), superoxide dismutase (SOD)-1 and heme oxygenase 1 (HMOX1) was found in serum of patients with anxiety 
FARMACIA, 2021, Vol. 69, 6

and depression [24]. Moreover, there is scientific evidence that anxiety and depression disorders are associated with gamma-Aminobutyric acid (GABA)ergic system dysfunction $[8,11]$.

Therefore, this medical condition represents a current and major issue for public health. Considering the possible side effects of classical medication and the hypotheses that anxiety disorders are highly comorbid with other mental disorders, the need of an alternative therapy, is urgently necessary.

Hypericin and its derivatives have been extensively studied, mainly for their antitumor, antiviral and antidepressant properties [17], but not considerable attention has been given to the anxiolytic effect of these compounds. Moreover, the animal models, although limited in terms of fully replicating specific anxiety disorder features and symptoms, they still play an important role in understanding the mechanisms and developing new therapeutic approaches in anxiety [5]. In our previous study, we demonstrated the antioxidant and anti-inflammatory effects of the Hypericum $s p$. extracts $(\mathrm{HpE})$ on anxiety-like-behaviour in rats [28]. In addition to the previously reported data, this investigation focused on HMOX1 and GABA levels in rats' brain and their association with the anxietylike-behaviour.

As high contents of quercetin and quercetin derivatives were found in our $\mathrm{HpE}$, we choose quercetin as positive control for this study [28].

Based on these data, our study aimed to evaluate the effect of some isolated natural compounds (quercetin, Q) and Hypericum maculatum (HM) and Hypericum perforatum (HP) extracts on ambulatory activity and GABA levels, histopathological changes in hippocampus and frontal lobe and HMOX1 immunoreactivity in frontal cortex in rats with FG-7142 experimentalinduced anxiety. FG-7142 is an anxiogenic drug, partial inverse agonist for the benzodiazepine allosteric site, frequently used to induce anxiety in experimental models.

\section{Materials and Methods}

\section{Dry extracts}

One analysed extract was obtained from Hypericum perforatum and commercialized by Naturex France ${ }^{\circledR}$. The second extract was obtained from Hypericum maculatum as described by Sevastre-Berghian et al., 2019. Quantification of main compounds was performed by liquid chromatography-electrospray ionization-mass spectrometry (LC-ESI-MS) and previously published [28]. Determination of the hypericin and hyperforin content and high-performance liquid chromatography analysis of all polyphenolic compounds were previously described [28].

Animals and experimental design

Experimental study was approved by the Animal Ethics Board of "Iuliu Hațieganu" University, ClujNapoca, Romania, and by the Direction for Veterinary
Surveillance and Food Safety in accordance with the recommendations of the Animal Welfare Directive 2010/63/EU. The animals were maintained under standard laboratory conditions, housed in a $12 \mathrm{~h}$ light $12 \mathrm{~h}$ dark cycle at room temperature $\left(24 \pm 2^{\circ} \mathrm{C}\right)$ with free access to a standard normocaloric pellet diet (VRF1) and water ad libitum. Sixty Wistar rats were used in the study. The animals were divided into 6 groups ( $\mathrm{n}=10$ animals/group) as following: carboxymethylcellulose $2 \%$ served as control (CMC), FG, Alprazolam + FG (APZ + FG), Q + FG, HM + FG, $\mathrm{HP}+\mathrm{FG}$. Alprazolam (APZ) as positive control (0.08 $\mathrm{mg} / \mathrm{Kg} \mathrm{bw}), \mathrm{Q}(30 \mathrm{mg} / \mathrm{kg} \mathrm{bw}), \mathrm{HM}$ and HP (350 $\mathrm{mg} / \mathrm{kg} \mathrm{bw}$ ) were orally administered for 21 days. In order to induce neurochemical and behavioural anxietylike effects in rats, one dose of $7.5 \mathrm{mg} / \mathrm{kg}$ bw FG7142 , dissolved in carboxymethylcellulose $2 \%$, was intraperitoneally administered on the $22^{\text {nd }}$ day of experiment, 1 hour before the behavioural tests, open field test (OFT) and elevated plus maze (EPM) [28]. FG-7142 (FG) was obtained from Sigma-Aldrich Chemicals GmbH (Germany). The GABA level was evaluated by ELISA in brain homogenate three hours after the FG-induction of anxiety. For this reason, the brain samples were taken under anaesthesia with an intraperitoneal injection of ketamine/xylazine cocktail (90 mg/kg bw ketamine and $10 \mathrm{mg} / \mathrm{kg}$ bw xylazine). The histopathological changes and immunohistochemistry reactivity in rats` brain were also analysed and then all animals were euthanized.

\section{Behavioural Testing}

Two different tests were used in our study, such as: OFT and EPM to assess the general locomotor activity and anxiety-like behaviour. The animals` activity was quantified by a visual tracking system (Smart Basic Software version 3.0 Panlab Harvard Apparatus) using specific mazes for rats (Ugo Basile Animal Mazes for Video-Tracking) [10, 28, 32].

Quantitative estimation of GABA levels by ELISA technique

The GABA level was evaluated in the hippocampus and frontal lobe by double antibody sandwich technique, using an ELISA kit according to the manufacturer's protocol (My BioSource. Com, Cat No. MBS269152). Results are expressed as $\mathrm{pg} / \mathrm{mg}$ protein of different treatment samples.

Histological and immunohistochemistry investigation of the brain

At the end of the experiment, three hours after the induction of anxiety, the rats were euthanized. For histological analysis, brain samples were fixed in $10 \%$ neutral buffered formalin, then embedded in paraffin in order to produce $5 \mu \mathrm{m}$ thick sections which were stained with haematoxylin-eosin (HE) for light microscopy (Optika B-383LD2 microscope). For histopathological analysis, we examined the global hippocampal structures and frontal lobe. For immunohistochemistry investigation, brain samples were fixed with either $4 \%$ paraform- 
FARMACIA, 2021, Vol. 69, 6

aldehyde in $0.1 \mathrm{M}$ phosphate buffer at $\mathrm{pH} 7.4$ for detecting HMOX1 distribution and reactivity. The brain samples were processed for whole-mount preparations. The paraffin-embedded sections, after rehydration, were subjected to enzymatic antigen retrieval with pepsin - hydrochloric acid $(\mathrm{HCl})(4 \mathrm{mg} / \mathrm{mL}$ in PBS $0.01 \mathrm{M}$ ) at $37^{\circ} \mathrm{C}$, for $10 \mathrm{~min}$ and then, the slides were treated with $3 \%$ hydrogen peroxide for $10 \mathrm{~min}$. After washing with tween 20/tris buffered saline (TBS) solution (TTBS), non-specific background staining was blocked with $10 \%$ bovine serum albumin (BSA) in TTBS pH 7.8 for 2 hours. The sections were then incubated at $4^{\circ} \mathrm{C}$ for 12 hours with a monoclonal anti-HMOX1 antibody (1:500, Sigma, Santa Cruz, CA). Then, the sections were washed with TTBS and treated with biotinylated - horseradish peroxidase (HRP) link universal (Dako, LSAB+ System-HRP) at room temperature, for $30 \mathrm{~min}$. All sections were washed in TTBS and incubated with streptavidin - peroxidase (Dako, LSAB + System - HRP) for $30 \mathrm{~min}$. The slides were washed three times with TTBS and were incubated with 3, 3 -diaminobenzidine (DAB + Chromogen, Dako, LSAB + System - HRP) for 5 min. To check the specificity of the immunohistochemistry tests, tissues in which primary antibodies were omitted from the initial incubation were also prepared.

Immunohistochemical reactions were scored according to a system based on the extent and intensity of the positive stain by the method of Toma et al. (2017), as follows: 0 negative reaction, $0.5-1+$ low reaction, $2+$ moderate reaction, $3+$ intense reaction, $4+$ very intense reaction [30].

Statistical Analysis

All experimental data were analysed by using ANOVA GraphPad Prism software, (GraphPad, San Diego, California, USA, version 6.0) and SPSS v.11.5 for Windows. One-way analysis of variance (ANOVA) was used, followed by Tukey's post hoc test, to determine statistically significant among the groups. All values in text and figures were expressed as mean \pm standard deviation. The limit of statistical significance was considered $\mathrm{p}<0.05$. $* \mathrm{p}<0.05 ; * * \mathrm{p}<0.01$; *** $\mathrm{p}<$ 0.001 .

\section{Results and Discussion}

\section{Behavioural studies}

A wide variety of experimental models are available for assessing anxiety - like behaviour in rodents, including behaviour tests (e.g. EPM, OFT, Zero maze, light/dark test, social interaction test, Corticosterone response, active passive avoidance, fear potentiated startle test), genetic models based on mutant mice with targeted deletions for the 5-hydroxytryptamine (5-HT) $1 \mathrm{~A}$ receptor gene, for corticotropin-releasing factor (CRF) gene or for the $\gamma_{2}$ subunit of the $\mathrm{GABA}_{\mathrm{A}}$ receptor; or pharmacological ones [5,9].
Partial inverse agonist at the benzodiazepine allosteric site of the GABAA receptor, the FG-7142 has been chosen to induce neurochemical and behavioural anxietylike effects in rats by modulating the GABA-induced chloride flux and interacting with the serotoninergic, dopaminergic, cholinergic and noradrenergic modulatory systems of the anxiety-related neural network [7]. Alprazolam, in a dose of $0.08 \mathrm{mg} / \mathrm{kg}$ bw was chosen as the standard anxiolytic drug (positive control) [28]. The effect of tested compounds on total and peripheral travelled distance, total and peripheral number of entries in OFT was illustrated in Figure 1. Figure 2 showed total travelled distance (A), travelled distance in closed arms (B), zone transition number (C) and number of entries in EMP. The OFT is used to assay general locomotor activity levels and anxiety in rodents in experimental studies [32]. Our results showed that Q and APZ $(p<0.05)$ significantly reversed the inhibitory effect of FG on total travelled distance (Figure 1A) and travelled distance in periphery (Figure 1B). Three weeks of $\mathrm{Q}$ administration, in comparison to FG treatment, increased significantly the locomotor activity (zone transition number and number of entries in periphery) $(\mathrm{p}<0.05)$ (Figure 1C, D). FG administration tended to diminish (0.69 times) the total travelled distance (Figure 1A), (0.7 times), the travelled distance in periphery (Figure $1 \mathrm{~B}),(0.76$ times), the zone transition number (Figure $1 \mathrm{C}$ ) and (0.75 times) the entries in periphery as compared to control group, but without statistical significance $(\mathrm{p}>0.05)$.

Even though, EPM is a commonly employed animal behavioural model of anxiety, this test is used to assay general locomotor activity levels, as well [32]. In the EPM, there was no significant effect of the natural compounds as compared to FG group on total and closed arms travelled distance ( $p>0.05$ ) (Figures 2A and 2B). APZ and $Q$ treated rats significantly made more entries in the EPM test as compared to FG (Figure 2C) and CMC (Figure 2D) group ( $<<0.05$ ). HP and HM administrations tended to improve general locomotion, but without any statistical significance $(p>0.05)$ (Figures 2A, 2B and 2C). The influence of 21 days of natural compounds administration on the anxiety behaviour, tested in OFT and EPM, was exemplified in Figure 3.

Regarding the anxiety behaviour in OFT, the APZ (p < $0.001), \mathrm{Q}(\mathrm{p}<0.001), \mathrm{HM}(\mathrm{p}<0.05)$ and HP $(\mathrm{p}<0.001)$ treated rats travelled significantly greater distance in the centre of open field arena as compared to anxiety induced - group (FG) (Figure 3A). HP group $(\mathrm{p}<0.01)$ made more entries in centre as compared to $\mathrm{FG}$ group (Figure 3B). APZ ( $<<0.05), Q(p<0.001)$ and HP $(\mathrm{p}<0.001)$ groups spent more time in the central part of the arena as compared to FG treated group (Figure 3C). Quercetin administration enhanced the travelled distance as compared to HM treatment $(\mathrm{p}<0.001)$ and the time spent in the centre of the open field as compared to both $\mathrm{HM}$ and $\mathrm{APZ}(\mathrm{Q}+\mathrm{FG} v s . \mathrm{HM}+\mathrm{FG}$, 
$\mathrm{p}<0.01 ; \mathrm{Q}+\mathrm{FG} v s . \mathrm{APZ}+\mathrm{FG}, \mathrm{p}<0.01$ ) (Figures 3A and $3 \mathrm{C})$. The HP treated group exhibited a significantly higher number of entries $(p<0.01)$ and spent more time in the centre of the apparatus as compared to HM

A

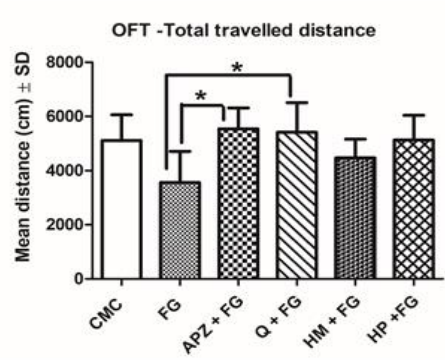

B

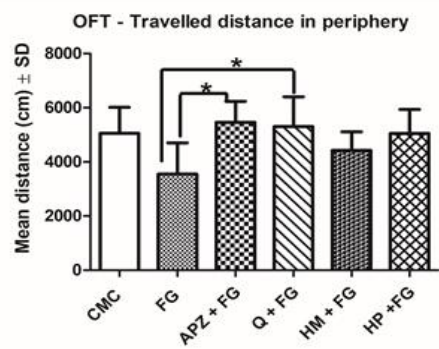

group ( $\mathrm{p}<0.05$ ) (Figures 3B and 3C). Conversely, FG administration diminished the travelled distance $(\mathrm{p}<0.05)$ and the time spent $(\mathrm{p}<0.001)$ in the centre as compared to the control group (Figures $3 \mathrm{~A}$ and $3 \mathrm{C}$ ).

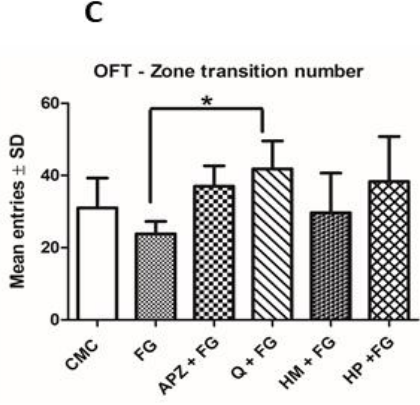

D

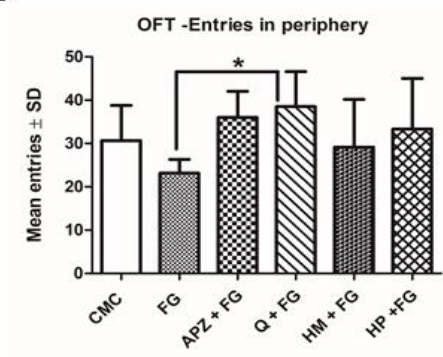

Figure 1.

The effects of natural compounds on total travelled distance (A) and peripheral (B) travelled distance and also on zone transition number (C) and peripheral (D) number of entries in OFT

$\mathrm{Q}$ and APZ increased significantly total travelled distance and distance travelled in periphery compared to FG group (p $<0.05)$.

$\mathrm{Q}$ enhanced the zone transition number and number of entries in periphery compared to FG group ( $\mathrm{p}<0.05$ ). Each group consisted of 10 rats. Results are expressed as mean $\pm \mathrm{SD}$;

$* \mathrm{p}<0.05 ; * * \mathrm{p}<0.01 ; * * \mathrm{p}<0.001$.

A

EPM - Total travelled distance

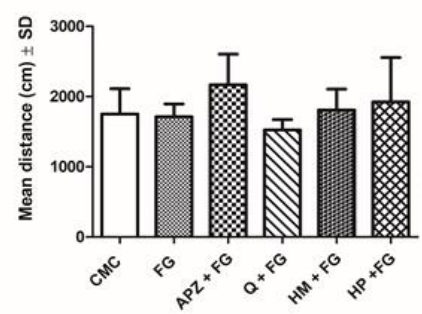

B

EPM - Travelled distance in closed arms

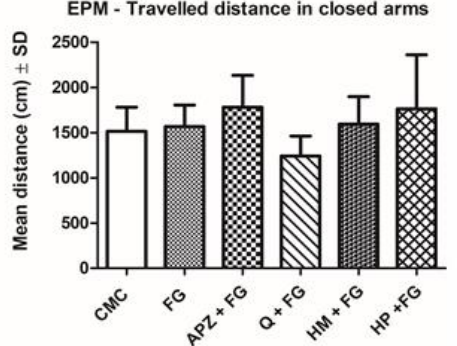

C

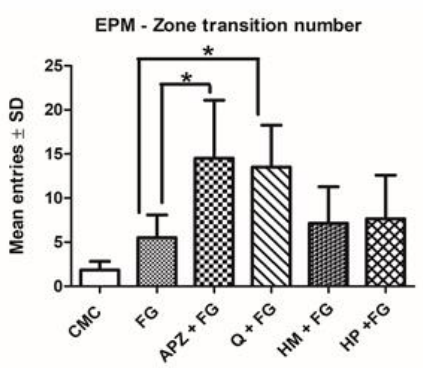

D

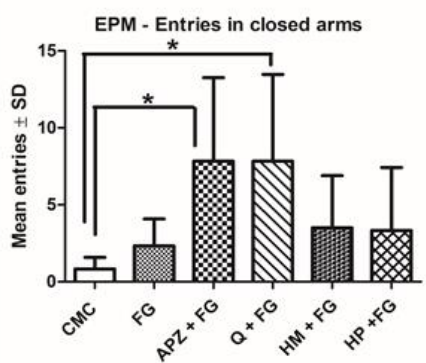

Figure 2.

Total travelled distance (A), travelled distance in closed arms (B), zone transition number (C) and number of entries in elevated plus maze (EPM) in rats treated with natural compounds (D).

$\mathrm{Q}$ and APZ increased number of entries and zone transition number in EPZ compared to control group ( $\mathrm{p}<0.05)$. Each group consisted of 10 rats. Results are expressed as mean $\pm \mathrm{SD} ; * \mathrm{p}<0.05 ; * * \mathrm{p}<0.01 ; * * * \mathrm{p}<0.001$. 


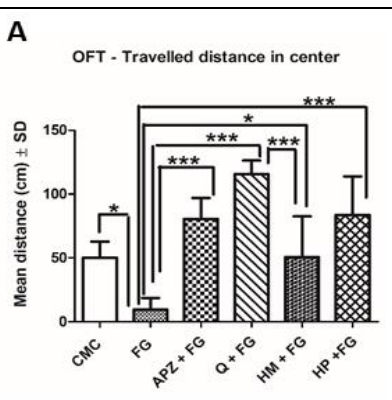

D

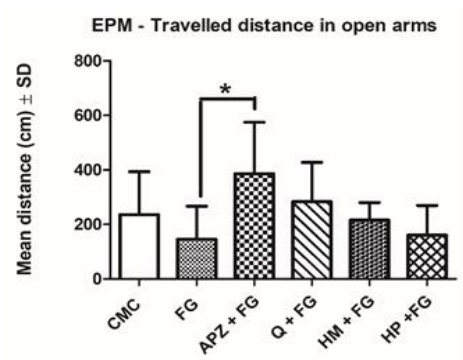

B

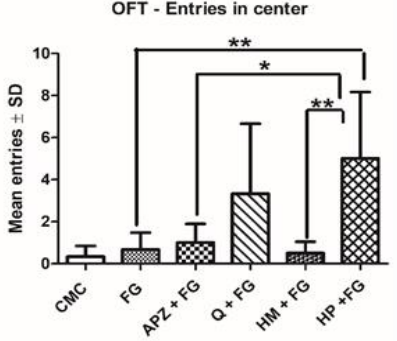

$\mathbf{E}$

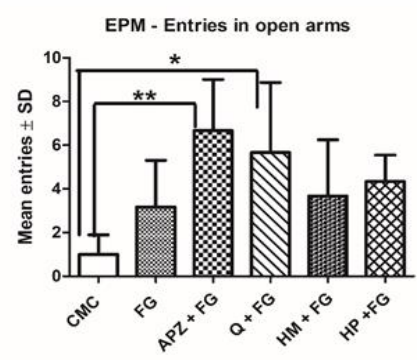

C

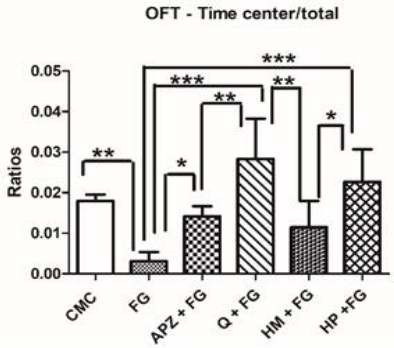

$\mathbf{F}$

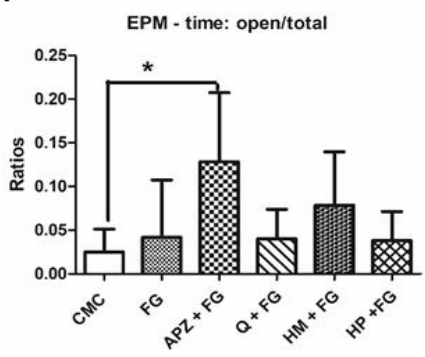

Figure 3.

The anxiety behaviour in Open Field Test (OFT) (A, B, C) and in Elevated Plus Maze (EPM) of animals treated with natural compounds $(\mathrm{D}, \mathrm{E}, \mathrm{F})$

Hypericum sp. increased travelled distance in centre, number of entries in centre and time spent in centre/total time, especially HP compared to FG group. Q enhanced travelled distance in centre, time spent in centre/total time, number of entries in open arm compared to FG group. Each group consisted of 10 rats. Results are expressed as mean \pm SD; $* \mathrm{p}<0.05 ; * * \mathrm{p}<0.01 ; * * \mathrm{p}<0.001$.

EPM has been successfully used to assess anxietylike behaviour in basic research, based on the natural tendency of rodents to explore novel environments [32]. The animals typically spend greater amount of time exploring the periphery of the arena or the closed arms of a maze, usually in contact with the walls, rather than the unprotected centre area. Conversely, more time spent, higher travelled distance and more entries made in the open arms of the EPM test apparatus during a 5 min test session can be considered as anxiolytic-like behaviour. All three previously mentioned items tended to be increased in the Q, HM and HP groups, but the differences for anxiety behaviour in EPM were not statistically significant $(p>0.05)$ (Figures 3D, 3E and 3F). In EPM, APZ group exhibited significantly higher travelled distance in open arms as compared to FG group ( $\mathrm{p}<0.05$ ) (Figure 3D).

Our findings showed that the anxiogenic FG-7142 reduced significantly the time spent and the travelled distance in the centre of the open field test. The rats exhibited a decreased general and peripheral locomotion in OFT, without statistical significance. In EPM tests, the total travelled distance and travelled distance in open arms tended to decrease, even though, there was no statistical difference between the anxious and the control group. The behavioural changes were also comparable with previous studies, which found that $7.5 \mathrm{mg} / \mathrm{kg}$ bw i.p. increased anxiety-like behaviour in rodents [19].

Apart from flavonoids, other constituents of Hypericum $s p .$, such as naphthodianthrones (hypericin, pseudo- hypericin) and prenylated acylphloroglucinols (hyperforin and adhyperforin) are responsible for Hypericum sp. extracts (HpE) beneficial effects [23].

Several studies have proved that hyperforin, the lipophilic chemical constituent, is an important potent uptake inhibitor of serotonin (5-HT), dopamine (DA), noradrenaline (NA), GABA and L-Glutamate in brain [34]. Thus, the anxiolytic activity of $\mathrm{HpE}$ could be explained either by modulation of GABA-ergic neurotransmission or by regulation of serotonin levels in various brain areas.

Our results demonstrated the anxiolytic-like-effect of HP in OFT test, such as the animals spent more time in the centre. HM treated rats also displayed low anxiety as they travelled greater distance in the centre of the field. Hence, our data are in agreement with previous studies that have shown the efficacy of $\mathrm{HpE}$ in a variety of nervous system disorders, including anxiety and depression in diabetic and non-diabetic rats [3]. Regarding the behavioural effects of quercetin in our study, there was an increase in general activity, revealed by significantly higher scores in peripheral and total number of entries and by peripheral and total travelled distance, assessed in OFT. Besides, based on the EPM test results, quercetin administration improved the general locomotion (increased zone transition number and entries in closed arms), as well. Quercetin demonstrated anxiolytic-like-effect in OFT as it enhanced the travelled distance and the time spent in centre part of the arena. Further, the quercetin treated rats made more 
entries in the open arms of the EPM as compared to controls.

\section{Quantitative estimation of brain GABA levels}

As the main constituents of $\mathrm{HpE}$ may regulate the neurotransmitters, the GABA levels in hippocampus and frontal lobes were assessed. The effects of natural compounds administration on the expression on the GABA levels in the different areas of brain were exemplified in Figure 4 (A and B).
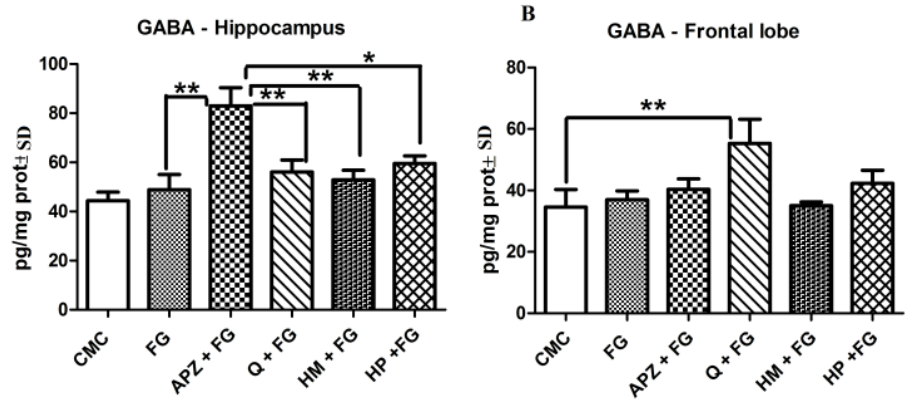

Figure 4.

The GABA levels in the hippocampus (A) and frontal lobe (B) of rats treated with natural compounds $\mathrm{Q}$ increased GABA levels in frontal lobe homogenate compared to CMC group $((\mathrm{p}<0.01)$. Each group consisted of 5 rats. Results are expressed as mean $\pm \mathrm{SD} ; * \mathrm{p}<0.05 ; * * \mathrm{p}<0.01 ; * * * \mathrm{p}<0.001$

In the hippocampus, significantly higher levels of GABA were recorded in the APZ group as compared to all other groups $(\mathrm{APZ}+\mathrm{FG} v s . \mathrm{FG}, \mathrm{p}<0.01 ; \mathrm{APZ}+$ FG vs. CMC, p < 0.001; APZ + FG vs. Q, p < 0.01; $\mathrm{APZ}+\mathrm{FG} v s$. HM, p < 0.01; APZ + FG vs. HP, p < 0.05 ), as measured by ELISA (Figure 4A). In frontal lobe, $\mathrm{Q}$ administration enhanced the GABA levels as compared to CMC group ( $<$ < 0.01) (Figure 4B).

In hippocampus, the GABA levels were significantly elevated by Alprazolam administration. Even though, Q, HM and HP tended to increase the GABA levels, their effects were significantly weaker in comparison to APZ. Interestingly, in frontal lobe, HM and HP exerted similar effects to APZ, while Q managed to increase the GABA levels as compared to the control group. These contradictory findings between different brain regions can be partially explained by regional heterogeneous distribution of GABA - benzodiazepine receptors [26].

Some authors revealed that quercetin administration in mice increased the social interaction time and decreased immobility time, thus indicating anxiolytic and antidepressant-like effect. There is also evidence that quercetin attenuates stress-induced behavioural and biochemical effects by decreasing the corticotrophin releasing factor (CRF) expression in the brain $[2,16]$. Jung and Lee (2014) reported the anxiolytic-like effect of quercetin, as it significantly increased the time spent in the open arms and the frequency of open arm entries in the EPM test. In addition, the authors concluded that quercetin's effect was $\mathrm{GABA}_{\mathrm{A}-\mathrm{\rho}}$ receptors mediated as long as a trans-4-aminocrotonic acid (a GABA $\mathrm{A}_{\mathrm{A}-\rho}$ agonist) reversed the anxiolytic-like activity of quercetin [16].

Histopathological and immunohistochemistry analysis in the brain

As mentioned by scientific studies, oxidative stress may be related to inflammation and anxious behaviour, thus we also assessed, in a previous article, the oxidative stress parameters and the levels of various cytokines, in the same brain areas.
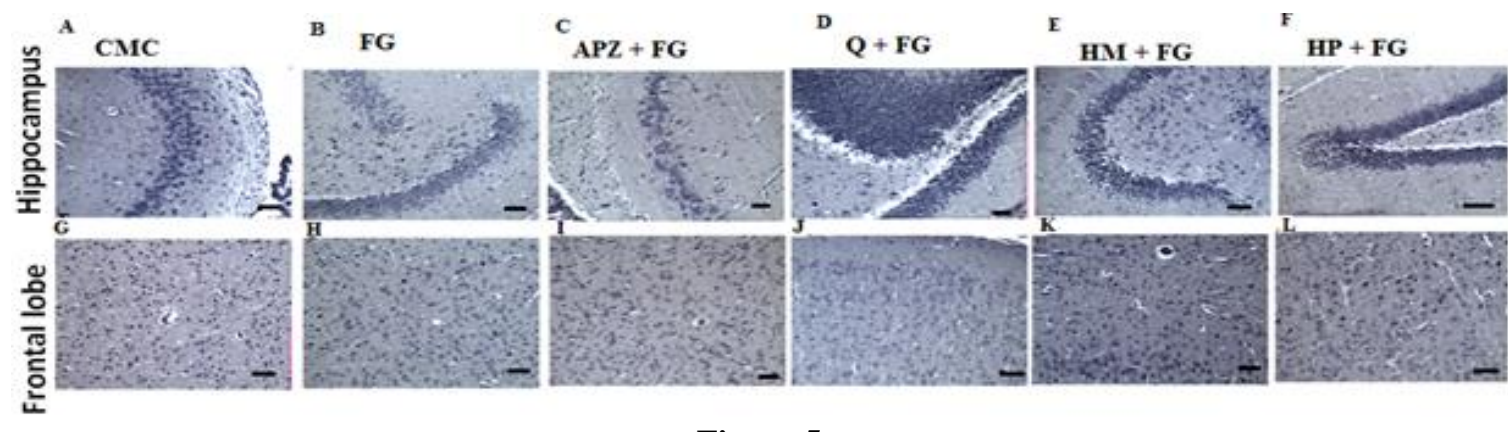

Figure 5.

Histopathological images of the hippocampus and frontal cortex in rats treated with natural compounds. A, B, C, D, E, F showed the histological features of CA3 in the hippocampus and G, H, I, J, K, L showed the morphology of frontal cortex

Magnification: $\times 200$. H\&E staining. Scale bar $=20 \mu \mathrm{m}$ 
As the amygdala, medial prefrontal cortex, anterior cingulated cortex appears to be involved in the regulation of anxiety, we histologically examined the hippocampus and the frontal lobe [22]. Moreover, the heme oxygenase 1 (HMOX1) expression was imunohistochemically evaluated in frontal lobe. The effects of natural compounds administration on the micromorphology of the hippocampus and frontal cortex were illustrated in Figure 5.

The brain tissue sections evaluated by morphometry revealed dilated capillaries and few hyperchrome neurons in the frontal cortex of CMC group. Hippocampus did not show any significant changes. Normal aspects of the frontal cortex and hippocampus with slight dilation of the frontal peri-gliocytes areas were observed in the anxiogenic drug treated group. In the Alprazolam treated group slight microglia proliferations were identified in the frontal cortex. Hippocampal formation showed a normal architecture, without gliosis-like changes or hypoxic-related injuries. The quercetin group showed dilated cortical capillaries in the frontal lobe and a normal morphology of the hippocampus. Capillaries dilation and slight gliocytes proliferation in the frontal cortex associated with few hyperchrome neurons were observed in the HM group.

The hippocampus did not show any significant changes. The animals treated with HP showed dilated cortical capillaries in the frontal lobe and intact global morphology of the hippocampal neurons.

The effects of natural compounds administration on the heme oxygenase 1 (HMOX1) expression in the frontal cortex were illustrated in Figure 6.
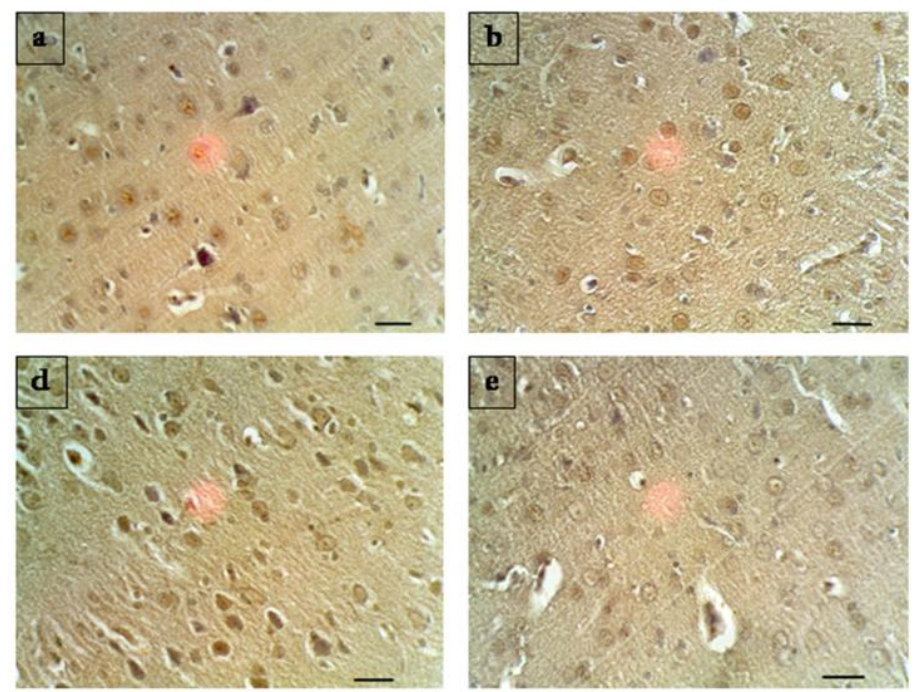

Figure 6.
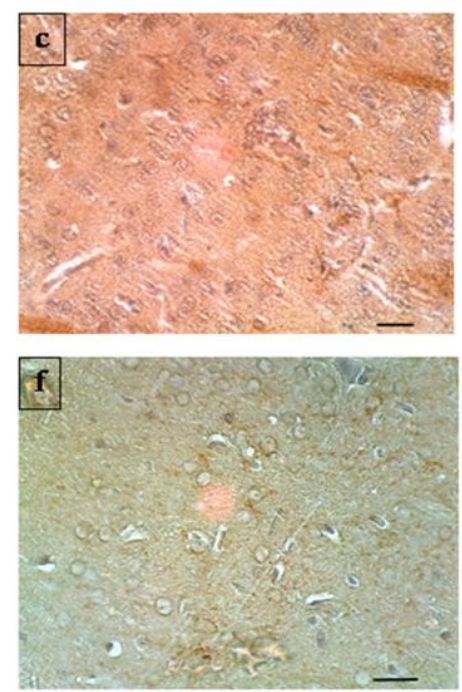

The immunoreactivity of HMOX1 in the frontal cortex of animals treated with natural compounds. a, b , c, d, e, f showed HMOX1 immunoreactivity in frontal cortex of CMC group (a) and treated groups with FG (b), FG + APZ (c), Q + FG (d), HM + FG (e) and HP + FG (f). x200, scale bar $=20 \mu \mathrm{m}$.

As one of the pivotal structures involved in cognitive disorders, the frontal cortex was also examined on the heme oxygenase 1 (HMOX1) expression. HMOX1 immunoreactivity in the frontal cortex was increased in FG (Figure 6b), FG+APZ (Figure 6c) and Q+FG (Figure 6d) group, with frequent perinuclear expression, in a range between 3 - 3.5 intensity score. As compared to the CMC group (Figure 6a), Hypericum sp. extracts slightly stimulated HMOX1 in frontal cortex (HM + FG; Figure 6e; HP + FG; Figure 6f). HMOX1 was scored as $0.5 / 1+$ and $2+$ respectively. The highest HMOX1 immunoreactivity was observed in the Q + FG group (HMOX1 score: 3.5). Hypericum sp. extracts decreased HMOX1 expression in the frontal cortex as compared to $\mathrm{Q}+\mathrm{FG}$ group $(\mathrm{HM}+\mathrm{FG}$ score: 0.5/1+; HP + FG score: 2 ).

Heme oxygenase 1 (HMOX1) may play a role in cellular and tissue protection by exerting antioxidant, anti-inflammatory, antiapoptotic and immunomodulatory effects [1]. This enzyme catalyses the cleavage of the heme to carbon monoxide, ferrous iron and biliverdin transformed by reduction to bilirubin [25]. There is little data on the role and activity of HMOX1 enzyme in depression. It seems that HMOX1 has neuroprotective role and improves the blood barrier damage induced by oxidative stress and inflammation, the effect being amplified by natural compounds [36]. Thus, various antioxidants, such as curcumin [20] quercetin [33] or allicin [13] have the ability to induce HMOX1 expression in human cells. However, the increased expression of HMOX 1 is not required for its possible beneficial effects; the HMOX1 is normally expressed at low levels in most tissues, but also, being highly inducible by a variety of stimuli including free heme, hydrogen peroxide, prostaglandins, peroxynitrite, and pro-inflammatory cytokines [35].

Shih et al. (2018) demonstrated that hypericin induced a down-regulation of HMOX1 as an inhibition pathway 
of hepatitis $C$ virus replication [29]. In brain structures, the increased expression of heme oxygenase-1, by hypericin-induced proteasome inhibition, protected astrocytes from heme- mediated oxidative injury [27]. Conversely, Buytaert et al., (2006) described that hypericin-based therapy, combined with photodynamic therapy, inhibited p38 mitogen activated protein kinase (MAPK), a key regulator of HMOX1 expression [4, 12]. In our study, only quercetin induced an increase of HMOX1 expression in the frontal lobe while the two natural extracts reduced its immunoreactivity. These results suggested that the enzyme was induced by oxidative stress and inflammation associated with anxiety in FG group, phenomenon amplified by Q and APZ administration probably as neuroprotective mechanism. The effect exerted by the two extracts on HMOX1 was lower than that of quercetin probably due to a moderate antioxidant activity.

Histopathologically, no significant microscopic changes were found in between the groups. Our data showed that anxious rats had no significant degree of histological brain damage, thus sustaining a functional - related damage rather than a morphological one.

\section{Conclusions}

In conclusion, our study demonstrates that quercetin (30 mg/kg bw), Hypericum maculatum, Hypericum perforatum $(350 \mathrm{mg} / \mathrm{kg}$ bw) improved the central locomotion, mainly in OFT. Quercetin and alprazolam enhanced the general locomotion both in OFT and EPM, and additionally increased the exploration behaviour in the open arms of the EPM. Alprazolam elevated the GABA levels in hippocampus of the anxious rats, while quercetin exerted the same effect in the frontal lobe of the rodents. Quercetin administration increased HMOX1 expression, whereas Hypericum sp. extracts slightly decreased HMOX1 immunoreactivity in frontal cortex neurons.

\section{Acknowledgement}

This work was financially sustained by the Iuliu Haţieganu University of Medicine and Pharmacy, ClujNapoca, Romania (Internal grant no. 4945/23/08.03.2016).

\section{Conflict of interest}

The authors declare no conflict of interest.

\section{References}

1. Araujo JA, Zhang M, Yin F, Heme Oxygenase-1, Oxidation, Inflammation, and Atherosclerosis. Front Pharmacol., 2012; 3: 119: 1-17.

2. Bhutada P, Mundhada Y, Bansod K, Ubgade A, Quazi M, Umathe S, Mundhada D, Reversal by quercitin of corticotrophin releasing factor induced anxiety- and depression-like effect in mice. Prog Neuropsychopharmacol Biol Psychiatry, 2010; 34(6): 955-960.
3. Bukhari IA, Dar A, Behavioral profile of Hypericum perforatum (St. John's Wort) extract. A comparison with standard antidepressants in animal models of depression. Eur Rev Med Pharmacol Sci., 2013; 17: 1082-1089.

4. Buytaert E, Callewaert G, Hendrickx N, Scorrano L, Hartmann D, Missiaen L, Agostinis P, Role of endoplasmic reticulum depletion and multidomain proapoptotic BAX and BAK proteins in shaping cell death after hypericin-mediated photodynamic therapy. FASEB J., 2006; 20(6): 756-758.

5. Campos AC, Fogac MV, Aguiar DC, Guimaraes FS, Animal models of anxiety disorders and stress. Braz J Psychiatry., 2013; 35(Suppl 2): S101-S111.

6. Cominski TP, Jiao X, Catuzzi JE, Stewart, AL, Pang $\mathrm{KCH}$, The Role of the Hippocampus in Avoidance Learning and Anxiety Vulnerability. Front Behav Neurosci., 2014; 8: 273: 1-10.

7. Evans AK, Lowry CA, Pharmacology of the $\beta$ Carboline FG-7142, a Partial Inverse Agonist at the Benzodiazepine Allosteric Site of the GABAA Receptor: Neurochemical, Neurophysiological, and Behavioral Effects. CNS Drug Review, 2007; 13(4): 475-501.

8. Fogaça MV, Duman RS, Cortical GABAergic Dysfunction in Stress and Depression: New Insights for Therapeutic Interventions. Front Cell Neurosci, 2019; 13: 87: 1-20.

9. Fuchs E, Flügge G, Experimental animal models for the simulation of depression and anxiety. Dialogues Clin Neurosc., 2006; 8(3): 323-333.

10. Gamberini MT, Rodrigues DS, Rodrigues D, Pontes VB, Effects of the aqueous extract of Pimpinella anisum L. seeds on exploratory activity and emotional behavior in rats using the open field and elevated plus maze tests. J Ethnopharmacol., 2015; 168: 45-49.

11. Godfrey KEM, Gardner AC, Kwon S, Chea W, and Muthukumaraswamy SD, Differences in excitatory and inhibitory neurotransmitter levels between depressed patients and healthy controls: a systematic review and meta-analysis. J Psychiatr Res., 2018; 105: 33-44.

12. Hendrickx N, Dewaele M, Buytaer E, Marsboom G, Janssens S, Van Boven M, Agostinis P, Targeted inhibition of $\mathrm{p} 38 \alpha$ MAPK suppresses tumor-associated endothelial cell migration in response to hypericinbased photodynamic therapy. Biochem Biophys Res Commun., 2005; 337(3): 928-935.

13. Horev-Azaria L, Eliav S, Izigov N, Pri-Chen S, Mirelman D, Miron T, Savion N, Allicin up-regulates cellular glutathione level in vascular endothelial cells. Eur J Nutr., 2009; 48(2): 67-74.

14. www.weforum.org/agenda/2019/01/this-is-theworlds-biggest-mentalhealth-problem

15. Ioniță R, Postu PA, Cioancă $\mathrm{O}$, Mircea $\mathrm{C}$, Hăncianu M, Hrițcu L, Anxiolytic and antidepressant effects of Matricaria chamomilla hydroalcoholic extract in a rat model of scopolamine. Farmacia, 2019; 67(1): 68-72.

16. Jung JW, Lee S, Anxiolytic Effects of Quercitin: Involvement of GABAergic System. J Life Sci., 2014; 24(3): 290-296.

17. Karioti A, Bilia AR, Hypericins as Potential Leads for New Therapeutics. Int J Mol Sci., 2010; 11(2): 62-94. 
18. Krolow R, Arcego DM, Noschang C, Weis SN, Dalmaz C, Oxidative Imbalance and Anxiety Disorders. Curr Neuropharmacol., 2014; 12: 193-204.

19. Lukkes JL, Engelman G., Zelin NS, Hale MW, Lowry CA, Post-weaning social isolation of female rats, anxiety-related behavior, and serotonergic systems. Brain Res., 2012; 14(1443): 1-17.

20. Motterlini R, Foresti R, Bassi R, Green CJ, Curcumin, an antioxidant and anti-inflammatory agent, induces heme oxygenase- 1 and protects endothelial cells against oxidative stress. Free Radic Biol Med., 2000; 28(8): 1303-1312.

21. Moylan S, Maes M, Wray NR, Berk M, The neuroprogressive nature of major depressive disorder: pathways to disease evolution and resistance, and therapeutic implications. Mol Psychiatry, 2013; 18(5): 595-606.

22. Nuss $P$, Anxiety disorders and GABA neurotransmission: a disturbance of modulation. Neuropsychiatr Dis Treat., 2015; 11: 165-175.

23. Oniga I, Toiu A, Benedec D, Tomuţă I, Vlase L, Phytochemical analysis of Hypericum maculatum in order to obtain standardized extracts. Farmacia, 2016; 64(2): 171-174.

24. Robaczewska J, Kędziora-Kornatowska K, Kucharski R, Nowak M, Muszalik M, Kornatowski M Kędziora $\mathrm{J}$, Decreased expression of heme oxygenase is associated with depressive symptoms and may contribute to depressive and hypertensive comorbidity. Redox Rep., 2016; 21(5): 209-218;

25. Roetling JC, Song W, Schipper HM, Regan CS, Regan RF, Astrocyte Overexpression of Heme Oxygenase-1 Improves Outcome After Intracerebral Hemorrhage. Stroke, 2015; 46(4): 1093-1098.

26. Saad JMB, Eldrogi AF, Al-Tubuly RA, Aburaw SM, Neurobehavioral effect of alprazolam in presence of Ascorbic acid using albino rats. Lebda Med J., 2016; 2: 68-82.

27. Seitz G, Krause R, Fuchs J, Heitmann H, Armeanu $\mathrm{S}$, Ruck $\mathrm{P}$, Warmann SW, In vitro photodynamic therapy in pediatric epithelial liver tumors promoted by hypericin. Oncol rep., 2008; 20(5): 1277-1282.

28. Sevastre-Berghian AC, Toma VA, Sevastre B, Hanganu D, Vlase L, Benedec D, Oniga I, Baldea I, Olteanu D, Moldovan R, Decea N, Filip GA, Clichici SV. Characterization and biological effects of Hypericum Extracts on experimentally-induced - anxiety, oxidative stress and inflammation in rats. J Physiol Pharmacol., 2018; 69(5): 1-12.

29. Shih $\mathrm{C} \mathrm{M}, \mathrm{Wu} \mathrm{CH}, \mathrm{Wu}$ WJ, Hsiao YM, Ko JL, Hypericin inhibits hepatitis $\mathrm{C}$ virus replication via deacetylation and down-regulation of heme oxygenase1. Phytomedicine, 2018; 46:193-198.

30. Toma VA, Farcas AD, Parvu M, Silaghi-Dumitrescu R, Roman I, CA3 hippocampal field: cellular changes and its relation with blood nitro-oxidative stress reveal a balancing function of CA3 area in rats exposed to repeated restraint stress. Brain Res Bull., 2017; 130: 10-17.

31. Vlad R, Golu F, Toma A, Drăgănescu D, Oprea B, Chiper BI, Depression and anxiety in Romanian medical students: Prevalence and associations with personality. Farmacia, 2020; 68(5), 944-949.

32. Walf AA, Frye CA, The use of the elevated plus maze as an assay of anxiety-related behavior in rodents. Nat Protoc., 2007; 2(2): 322-328.

33. Yao P, Nussler A, Liu L, Hao L, Song F, Schirmeier, Nussler N, Quercetin protects human hepatocytes from ethanol-derived oxidative stress by inducing heme oxygenase-1 via the MAPK/Nrf2 pathways. $J$ Hepatol., 2007; 47(2): 253-261.

34. Zanoli P, Role of Hyperforin in the Pharmacological Activities of St. John's Wort. CNS Drug Reviews, 2004; 10(3): 203-218.

35. Zeligman JRD, Heme oxygenase- 1 and neurodegeneration: expanding frontiers of engagement. J Neurochem., 2009; 110(2): 469-485.

36. Zhao J, Moore AN, Redell JB, Dash PK, Enhancing expression of Nrf2-driven genes protects the blood brain barrier after brain injury. J Neurosci., 2007; 27(38): 10240-10248. 